\title{
Failure Dependence Analysis of Shear Walls with Different Openings under Fortification Earthquakes
}

\author{
Junfeng Zhu ${ }^{1}$, Donghui Zheng ${ }^{2} \&$ Yifan $\mathrm{Li}^{1}$ \\ ${ }^{1}$ College of Planning and Architectural Engineering, Henan University of Science and Technology, Luoyang, \\ China \\ ${ }^{2}$ Xuchang Tengfei Municipal Engineering Group Co., Ltd. \\ Correspondence: Junfeng Zhu, College of Planning and Architectural Engineering, Henan University of Science \\ and Technology, No. 263, Kaiyuan Road, Luolong District, Luoyang 471023, China. E-mail: \\ junfeng-zhu@163.com
}

Received: February 9, 2013

Accepted: May 6, 2013 Online Published: May 22, 2013

doi:10.5539/mer.v3n1p185

URL: http://dx.doi.org/10.5539/mer.v3n1p185

\begin{abstract}
It is necessary to study failure dependence problem in order to solve system reliability in the field of Civil Engineering. In this paper, failure dependence of reinforced concrete shear walls with different openings (including the whole shear wall, the shear wall with small opening, the coupled shear wall, the shear wall frame) are studied under fortification earthquakes using Monte Carlo method. The results demonstrate that failure of reinforced concrete shear walls with different openings is neither fully independent nor fully relevant. The number of failure dependent floors is about one-half total floors. The failure dependent floors are concentrated mainly in the upper part.
\end{abstract}

Keywords: failure dependence, shear walls with openings, fortification earthquakes

\section{Introducation}

Structural system reliability can be defined that the structural system completes the predetermined function of probability within the prescribed time and under specified conditions. It is an important parameter to evaluate the overall performance of the structure. "Unified standard for reliability design of engineering structures" (GB50153-92) has made clear that engineering structures should be designed according to structural system reliability when some conditions are provided. Structural system reliability design should select main failure modes according to the structural damage characteristics. Failure dependence of engineering structures can be defined that when a structure is effected by the same random interference source (meeting regional and simultaneity hypothesis), failure of its components are interrelated and are not independent of each other. It is very important for each unit failure to take into account reasonably in structural system reliability. For a seismic structure, failure of each floor has a certain correlation due to the same random interference source (earthquakes).

Reliability of failure dependent engineering system is studied (Wang \& Zhu, 1998). Failure dependence between structure and structure depends primarily on the intensity of natural disasters under natural disasters, the stronger intensity the greater dependence. Some failure dependence issues of building structures are discussed (Wang, 2001). It is tried to avoid using "failure mode of independence assumption" and "weakest constraint hypothesis" or using "most serious failure mode assumptions" and "constraints independence assumption" at the same time in the structural system reliability analysis. Failure modes dependence of structural system are considered under hazard loads by introducing a roughness index of load (Li \& Cheng, 2001). Effects of dependence on structural reliability are researched under earthquakes (Hong, 2000).

An improvement is suggested, using systems factors, which accounts for the different levels of damage implied by the various limit states (Galambos, 1990). The seismic reliability of two reinforced concrete buildings is evaluated (Saito, Abe, \& Shibata, 1997). The uncertainty of earthquake forces, the uncertainties of structural characteristics, such as lateral resistance and the first natural period of structures, are considered based on the statistics of existing building. The Bayesian parameter estimation technique is used to develop probabilistic displacement and strength capacity and demand models for reinforced concrete structural walls (Sasani, 
Kiureghian, \& Bertero, 2002). An approach to reliability calculation in performance-based design is presented using an important sampling simulation, with performance functions evaluated by localized interpolation of a response database (Foschi, Li, \& Zhang, 2002).Three probabilistic methods are presented for the prediction of potential seismic damage to low and mid-rise reinforced concrete building (Askan \& Yucemen, 2010).

\section{Analysis Procedure of Failure Dependence}

\subsection{Establishment of Mechanical Models}

Failure dependence analysis is based on reliability analysis of structures. It is necessary to establish mechanical model prior to reliability analysis. Reinforced concrete shear wall can be divided into four categories according to the size of hole. They are the whole shear wall $(\alpha<15 \%)$, the shear wall with small openings $(15 \% \leq \alpha<$ $30 \%)$, the coupled shear wall $(30 \% \leq \alpha<50 \%)$, the shear wall frame $(\alpha \geq 50 \%)$.

$$
\alpha=\frac{A_{\text {hole }}}{A_{\text {total }}} \times 100 \%
$$

Where

$\alpha-$ coefficient of hole.

$A_{\text {hole }}$-area of hole.

$A_{\text {totar }}$ total area of shear wall.

In this study, mechanical models of different reinforced concrete shear walls with openings are established, including the whole shear wall (abbreviation for wall A, $\alpha=0$ ), the shear wall with small openings (abbreviation for wall B, $\alpha=21 \%$ ), coupled shear wall (abbreviation for wall C, $\alpha=35 \%$ ), shear wall frame (abbreviation for wall $\mathrm{D}, \alpha=53 \%$ ). Fortification intensity is eight degree. Basic design acceleration of ground motion is $0.2 \mathrm{~g}$. Site classification is II. Physical dimensions of shear walls are shown in Table 1. Mechanical models of shear walls are shown in Figure 1-Figure 4.

Table 1. Physical dimensions of shear walls

\begin{tabular}{|c|c|c|c|c|c|c|}
\hline Type & $\begin{array}{c}\text { Number of } \\
\text { layers }\end{array}$ & $\begin{array}{l}\text { story height } \\
\text { (m) }\end{array}$ & $\begin{array}{l}\text { wall width } \\
\text { (m) }\end{array}$ & $\begin{array}{c}\text { wall } \\
\text { thickness (m) }\end{array}$ & $\begin{array}{c}\text { opening size } \\
(\text { width } \times \text { height })(\mathrm{m})\end{array}$ & $\begin{array}{l}\text { side pillar } \\
\text { (m) }\end{array}$ \\
\hline Wall A & 8 & 3.0 & 6.0 & 0.2 & - & $0.4 \times 0.4$ \\
\hline Wall $B$ & 8 & 3.0 & 6.0 & 0.2 & $1.8 \times 2.1$ & $0.4 \times 0.4$ \\
\hline Wall C & 8 & 3.0 & 6.0 & 0.2 & $3.0 \times 2.1$ & $0.4 \times 0.4$ \\
\hline Wall $D$ & 8 & 3.0 & 6.0 & 0.2 & $4.2 \times 2.1$ & $0.4 \times 0.4$ \\
\hline
\end{tabular}

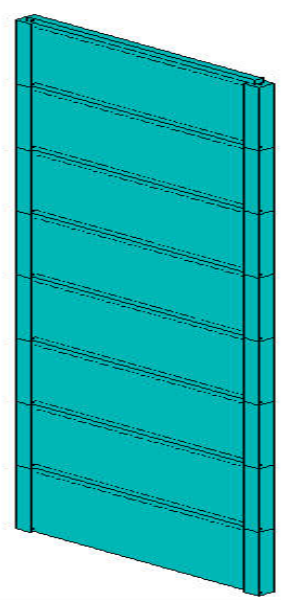

Figure 1. whole shear wall

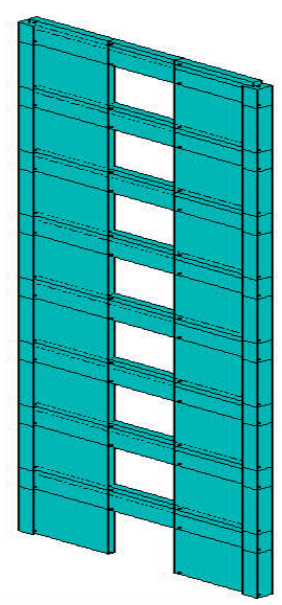

Figure 2. shear wall with small openings 


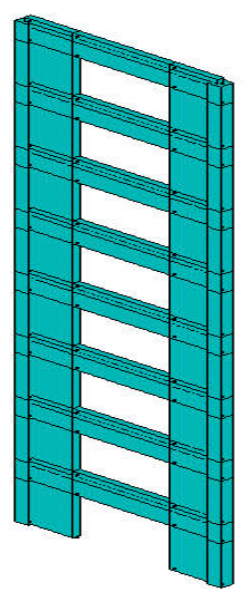

Figure 3. Coupled shear wall

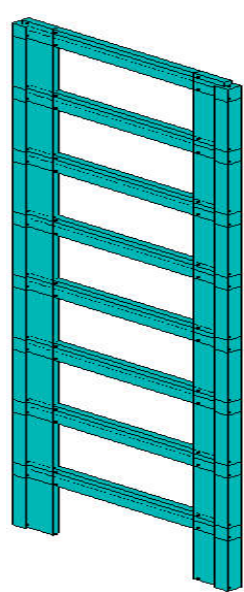

Figure 4. Wall frame

\subsection{Reliability Analysis}

Monte-Carlo method is a stochastic simulation method based on the probability and statistics theory. In this study, Monte-Carlo method is used for reliability analysis. The number of stochastic simulation is ten thousand times. Loads include vertical loads and horizontal loads. Vertical loads and horizontal loads are both random loads during reliability analysis. Vertical loads include structural weight and live loads. It is assumed that vertical loads obey normal distribution. Horizontal load is horizontal seismic action, and its distribution obeys extreme value I distribution. The horizontal seismic action is calculated by equivalent base shear method. The characteristic value of horizontal seismic action applied on story i-th can be determined by the following equations:

$$
\begin{gathered}
F_{i}=\frac{G_{i} H_{i}}{\sum_{j=1}^{n} G_{j} H_{j}} F_{E k} \\
F_{\mathrm{Ek}}=\alpha_{1} G_{\mathrm{eq}}
\end{gathered}
$$

Where

$F_{\mathrm{i}}$-characteristic value of horizontal seismic action applied on story i-th.

$\mathrm{G}_{i}, \mathrm{G}_{j}-$ representative values of gravity load concentrated at the story $\mathrm{i}$-th and $\mathrm{j}$-th.

$F_{\mathrm{Ek}}-$ characteristic value of the total horizontal seismic action of the structure.

$\alpha_{l}$-horizontal seismic influence coefficient corresponding to the fundamental period of the structure.

$\mathrm{G}_{e q}$-equivalent total gravity load of a structure, $\mathrm{G}_{e q}=0.85 \mathrm{G}$.

G-representative value of the total gravity load.

It is necessary to establish limit state equation when seismic reliability analysis is carried out. Limit state equation is based on structural failure criteria. At present, the main failure criteria of structures include (1) strength failure criterion, (2) energy failure criterion, (3) deformation failure criterion, and (4) deformationenergy double failure criterion. Deformation failure criterion has been widely used in practice because of its simplicity and better reflecting the maximum response of structures under seismic action.

In this study, the limit state equation is established according to seismic fortification goal of reinforced concrete shear wall structure under fortification earthquakes based on story drift. Limit state equation is shown in Table 2 according to GB50011-2010. 
Table 2. Limit State Equation

\begin{tabular}{cccc}
\hline Type & Limit State Equation & & State \\
\hline \multirow{3}{*}{ Fortification Earthquakes } & $Z=[\Delta u]-\Delta u$ & $Z>0$ & Repairable State \\
& & $Z=0$ & Limit State \\
& & $Z<0$ & Unprepairable State \\
\hline
\end{tabular}

Where

$[\Delta u]-$ limit value of story drift under fortification earthquakes, $[\Delta u]=[\theta] h$.

$[\theta]-$ limit value of story drift rotation under fortification earthquakes, $[\theta]=1 / 300$.

$h$-height of calculated story.

$\Delta u$-story drift under fortification earthquakes.

\subsection{Calculation of Failure Coefficients}

Every floor of story drift (random variable) can be got after finishing reliability analysis. Failure information can be known when story drift is compared with its limit value. When a floor is repairable state, its information is recorded as " 1 ". When a floor is unprepairable state, its information is recorded as " 0 ". A one-dimensional ordered sequence is formed when failure information is arranged in a certain order. Failure correlation coefficient can be calculated according to probability theory and mathematical statistics (Sheng, Xie, \& Pan, 2008) by the following formula:

$$
\rho_{i j}=\frac{\operatorname{cov}(i, j)}{\sigma_{i} \cdot \sigma_{j}}
$$

Where

$\rho_{i j}$-failure correlation coefficient between i-th floor and $\mathrm{j}$-th floor.

$\operatorname{cov}(i, j)$-covariance between $\mathrm{i}$-th floor and $\mathrm{j}$-th floor.

$\sigma_{i}$-standard deviation of i-th floor failure information.

$\sigma_{j}$-standard deviation of $\mathrm{j}$-th floor failure information.

\subsection{Judgement of Failure Dependence}

According to probabilistic networks technology (abbreviation for PNET), when failure correlation coefficient between two floors is larger than 0.7 , it can be considered that failure of these two floors is statistically correlative, or else failure of these two floors is statistically independent (Ang \& Tang, 1984).

\section{Analysis Results of Failure dependence}

\subsection{Failure Correlation Coefficients}

Failure correlation coefficients of reinforced concrete shear walls with different openings under fortification earthquakes are shown in Table 3. 
Table 3. Failure correlation coefficients

\begin{tabular}{|c|c|c|c|c|c|c|c|}
\hline \multicolumn{2}{|c|}{ Whole shear wall } & \multicolumn{2}{|c|}{ Wall with small opening } & \multicolumn{2}{|c|}{ Coupled shear wall } & \multicolumn{2}{|c|}{ Shear wall frame } \\
\hline $\begin{array}{l}\text { Related } \\
\text { interstory }\end{array}$ & $\begin{array}{l}\text { Correlation } \\
\text { coefficient }\end{array}$ & $\begin{array}{l}\text { Related } \\
\text { interstory }\end{array}$ & $\begin{array}{l}\text { Correlation } \\
\text { coefficient }\end{array}$ & $\begin{array}{l}\text { Related } \\
\text { interstory }\end{array}$ & $\begin{array}{l}\text { Correlation } \\
\text { coefficient }\end{array}$ & $\begin{array}{l}\text { Related } \\
\text { interstory }\end{array}$ & $\begin{array}{l}\text { Correlation } \\
\text { coefficient }\end{array}$ \\
\hline $1-2$ & 0.0000 & $1-2$ & 0.0000 & $1-2$ & 0.0000 & $1-2$ & 0.0000 \\
\hline $1-3$ & 0.0000 & $1-3$ & 0.0000 & $1-3$ & 0.0000 & $1-3$ & 0.0000 \\
\hline $1-4$ & 0.0000 & $1-4$ & 0.0000 & $1-4$ & 0.0000 & $1-4$ & 0.0000 \\
\hline $1-5$ & 0.0000 & $1-5$ & 0.0000 & $1-5$ & 0.0000 & $1-5$ & 0.0000 \\
\hline $1-6$ & 0.0000 & $1-6$ & 0.0000 & $1-6$ & 0.0000 & $1-6$ & 0.0000 \\
\hline $1-7$ & 0.0000 & $1-7$ & 0.0000 & $1-7$ & 0.0000 & $1-7$ & 0.0000 \\
\hline $1-8$ & 0.0000 & $1-8$ & 0.0000 & $1-8$ & 0.0000 & $1-8$ & 0.0000 \\
\hline $2-3$ & 0.0000 & $2-3$ & 0.5396 & $2-3$ & 0.5264 & $2-3$ & 0.6581 \\
\hline $2-4$ & 0.0000 & $2-4$ & 0.3734 & $2-4$ & 0.4294 & $2-4$ & 0.6397 \\
\hline $2-5$ & 0.0000 & $2-5$ & 0.3152 & $2-5$ & 0.3974 & $2-5$ & 0.7245 \\
\hline $2-6$ & 0.0000 & $2-6$ & 0.3108 & $2-6$ & 0.4254 & $2-6$ & 0.9485 \\
\hline $2-7$ & 0.0000 & $2-7$ & 0.3465 & $2-7$ & 0.4931 & $2-7$ & 0.5471 \\
\hline $2-8$ & 0.0000 & $2-8$ & 0.3937 & $2-8$ & 0.6450 & $2-8$ & 0.3647 \\
\hline $3-4$ & 0.4998 & $3-4$ & 0.6919 & $3-4$ & 0.8158 & $3-4$ & 0.9720 \\
\hline $3-5$ & 0.3158 & $3-5$ & 0.5842 & $3-5$ & 0.7549 & $3-5$ & 0.9083 \\
\hline $3-6$ & 0.2308 & $3-6$ & 0.5760 & $3-6$ & 0.8083 & $3-6$ & 0.6242 \\
\hline $3-7$ & 0.2125 & $3-7$ & 0.6422 & $3-7$ & 0.9368 & $3-7$ & 0.3601 \\
\hline $3-8$ & 0.2176 & $3-8$ & 0.7295 & $3-8$ & 0.8160 & $3-8$ & 0.2400 \\
\hline $4-5$ & 0.6319 & $4-5$ & 0.8443 & $4-5$ & 0.9254 & $4-5$ & 0.8829 \\
\hline $4-6$ & 0.4619 & $4-6$ & 0.8324 & $4-6$ & 0.9908 & 4-6 & 0.6068 \\
\hline $4-7$ & 0.4252 & $4-7$ & 0.9281 & $4-7$ & 0.8708 & $4-7$ & 0.3500 \\
\hline $4-8$ & 0.4353 & $4-8$ & 0.9484 & $4-8$ & 0.6657 & $4-8$ & 0.2333 \\
\hline $5-6$ & 0.7310 & $5-6$ & 0.9859 & $5-6$ & 0.9340 & $5-6$ & 0.6872 \\
\hline $5-7$ & 0.6730 & $5-7$ & 0.9097 & $5-7$ & 0.8058 & $5-7$ & 0.3964 \\
\hline $5-8$ & 0.6889 & $5-8$ & 0.8008 & $5-8$ & 0.6160 & $5-8$ & 0.2642 \\
\hline $6-7$ & 0.9207 & $6-7$ & 0.8969 & $6-7$ & 0.8628 & $6-7$ & 0.5768 \\
\hline $6-8$ & 0.9425 & $6-8$ & 0.7895 & $6-8$ & 0.6596 & $6-8$ & 0.3845 \\
\hline $7-8$ & 0.9769 & $7-8$ & 0.8803 & $7-8$ & 0.7644 & $7-8$ & 0.6665 \\
\hline
\end{tabular}


Firstly, it can be seen from table 3 that failure correlation coefficients of the whole shear wall from the fifth floor to the eighth floor are larger 0.7 or closer to 0.7 under fortification earthquakes. It indicates that failure of the whole shear wall from the fifth floor to the eighth floor is statistically correlative and failure of other floors is statistically independent under fortification earthquakes.

Secondly, it can be seen from table 3 that failure correlation coefficients of the shear wall with small opening from the fourth floor to the eighth floor are larger 0.7 under fortification earthquakes. It indicates that failure of shear wall with small opening from the fourth floor to the eighth floor is statistically correlative and failure of other floors is statistically independent under fortification earthquakes.

Thirdly, it can be seen from table 3 that failure correlation coefficients of the coupled shear wall from the third floor to the eighth floor are larger 0.7 or closer to 0.7 under fortification earthquakes. It indicates that failure of coupled shear wall from the third floor to the eighth floor is statistically correlative and failure of other floors is statistically independent under fortification earthquakes.

Finally, it can be seen from table 3 that failure correlation coefficients of the shear wall frame from the third floor to the fifth floor are larger 0.7 under fortification earthquakes. It indicates that failure of shear wall frame from the third floor to the fifth floor is statistically correlative and failure of other floors is statistically independent under fortification earthquakes.

\subsection{Schematic Diagram of Failure Dependence}

Failure correlation schematic diagrams of shear walls with different openings are shown in Figure 5 Figure 8 respectively according to Table 3. Light-colored part represents failure between these floors is independent under fortification earthquakes. The pink part represents failure between these floors is relevant under fortification earthquakes.

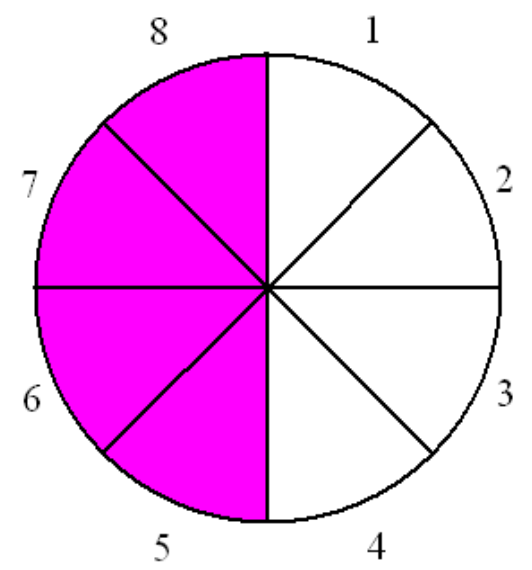

Figure 5. Sketch for the whole shear wall

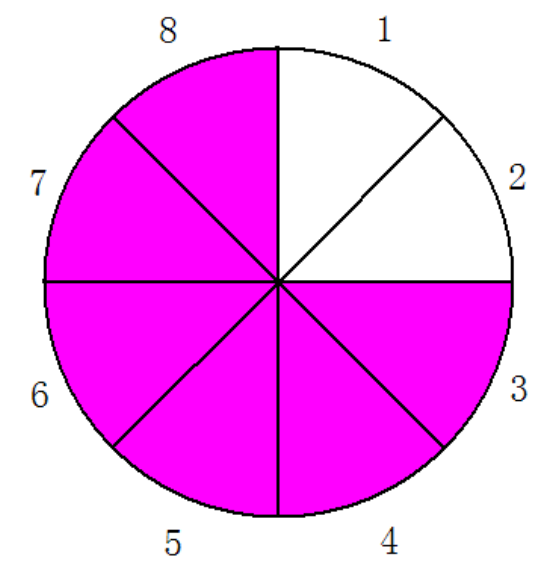

Figure 7. Sketch for the coupled shear wall

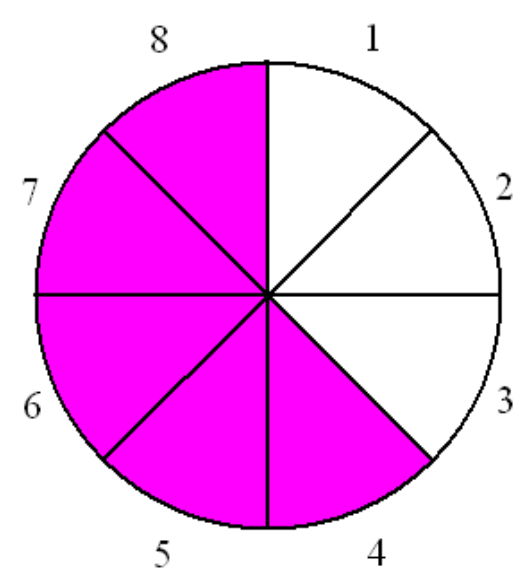

Figure 6. Sketch for the shear wall with small openings

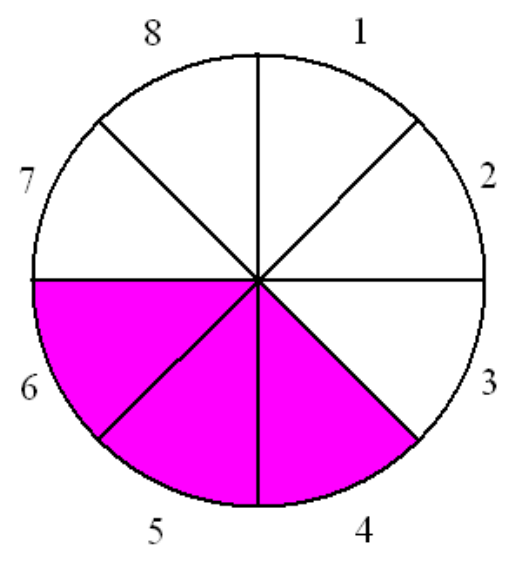

Figure 8. Sketch for the shear wall frame 


\subsection{Statistical Results of Story Drift}

Story drift is an important control index for reinforced concrete structure. It is important to know scope of story drift for seismic structure under earthquakes. Story drifts statistical results of shear walls different openings under fortification earthquakes are shown in Figure 9-Figure 12, including maximum value, minimum value and mean value.

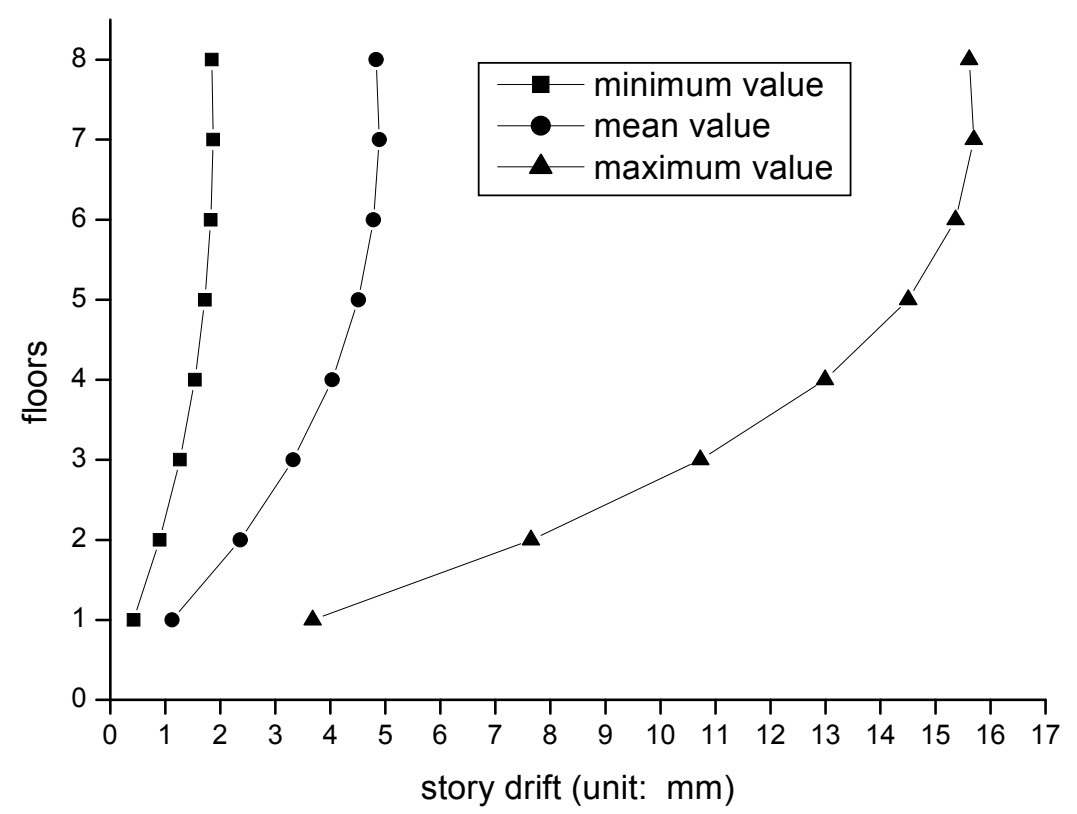

Figure 9. Story drift statistical result of the whole shear wall

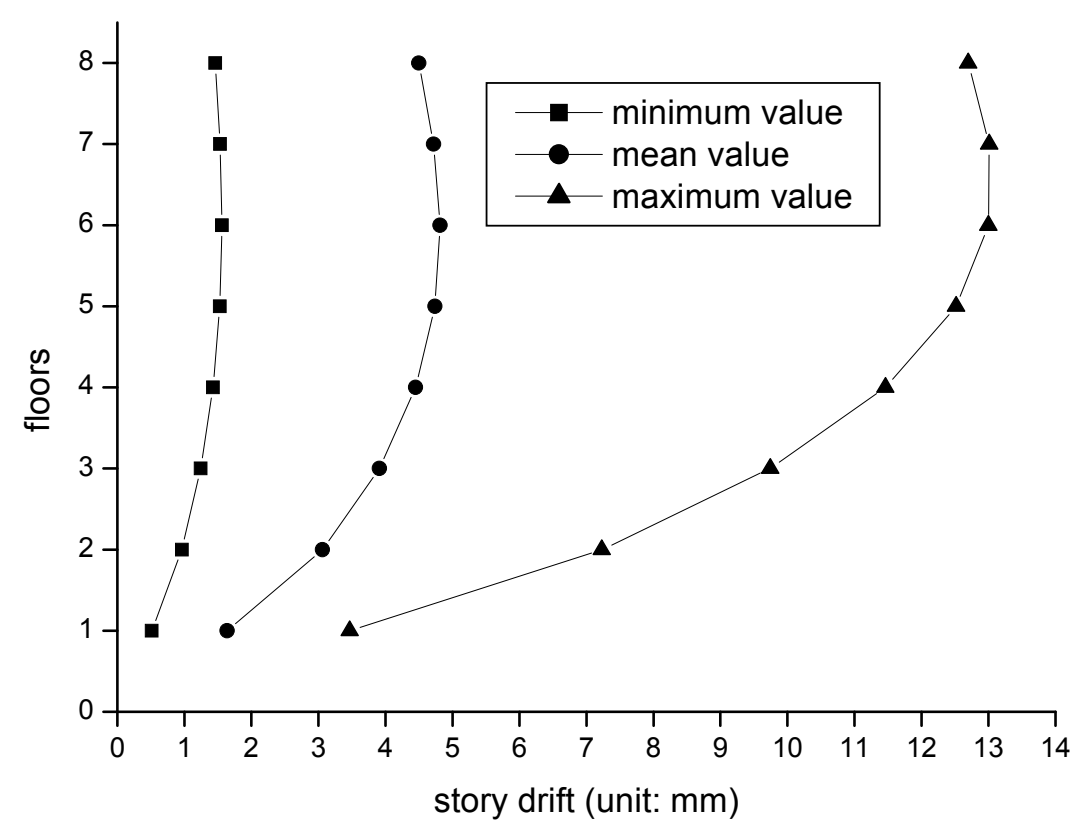

Figure 10. Story drift statistical result of the shear wall with small openings 


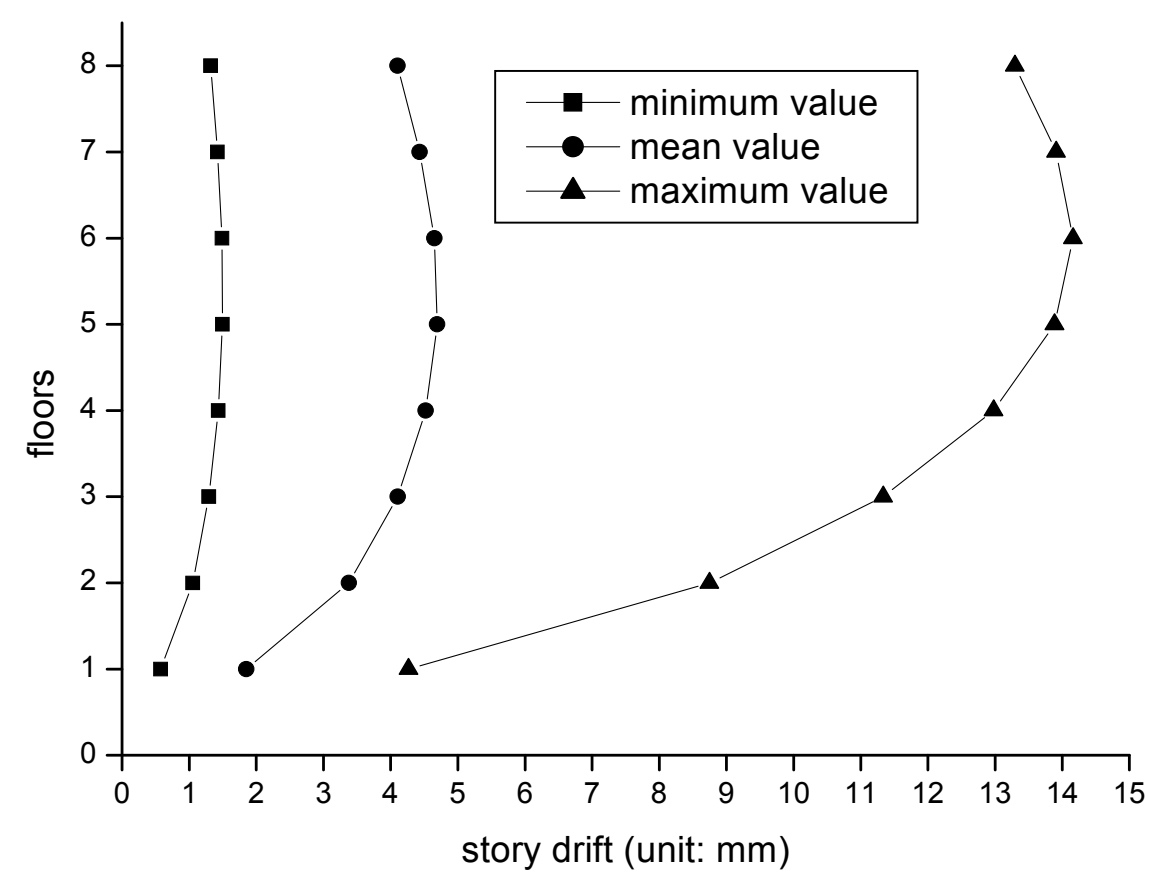

Figure 11. Story drift statistical result of the coupled shear wall

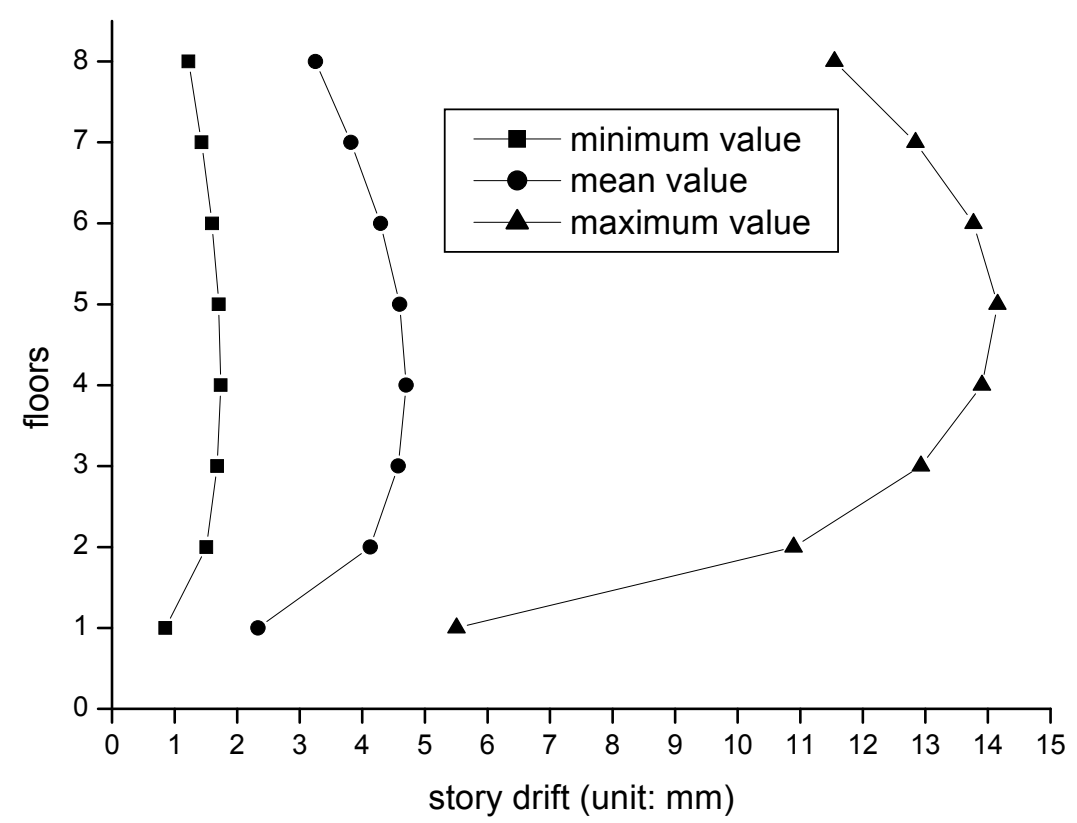

Figure 12. Story drift statistical result of the shear wall frame

\section{Conclusion}

In summary the above discussion, some conclusions can be drawn as follows. The failure between the floors of shear walls different openings is neither fully independent, nor entirely relevant under fortification earthquakes. The number of failure dependent floors is about one-half total floors. The failure dependent floors are concentrated mainly in the upper part. 


\section{Acknowledgments}

The authors are grateful to the editor and a referee whose helpful comments improved the presentation. This work is supported by key projects of Office of Science and Technology of Henan Province (092102310247).

\section{References}

Ang, A. H.-S., \& Tang, W. H. (1984). Probability concepts in engineering planning and design. Volume II: decision, risk and reliability, 504-509. New York: John Wiley \& Sons.

Askan, A., \& Yucemen, M. S. (2010). Probabilistic methods for the estimation of potential seismic damage: Application to reinforced concrete buildings in Turkey. Structural Safety, 32(4), 262-271. http://dx.doi.org/10.1016/j.strusafe.2010.04.001

Foschi, R. O., Li, H., \& Zhang, J. (2002). Reliability and performance-based design: a computational approach and applications. Structural Safety, 24(2-4), 205-218. http://dx.doi.org/10.1016/S0167-4730(02) 00025-5

Galambos, T. V. (1990). Systems reliability and structural design. Structural Safety, 7(2-4), 101-108. http://dx.doi.org/10.1016/0167-4730(90)90060-3

He, Z. Y. (1994). Failure-Dependence of Engineering Structures under Action of a Stochastically Disturbing Source. Earthquake Engineering and Engineering Vibration, 14(2), 76-85.

Hong, H. P. (2000). Effect of Dependence on Structural Reliability for earthquake loading. Earthquake Engineering and Engineering Vibration, 20(4), 8-13.

Li, G., \& Cheng, G. D. (2001). Correlation between Structural Failure Modes and Calculation of System Reliability under Hazard Loads. Enginering Mechanics, 18(3), 1-9.

National Standard of the People's Republic of China. (1992). Unified standard for reliability design of engineering structures (GB50153-92). Beijing: China Planning Press.

National Standard of the People's Republic of China. (2010). Code for seismic design of buildings (GB50011-2010). Peking: China Architecture \& Building Press.

Saito, T., Abe, S., \& Shibata, A. (1997). Seismic damage analysis of reinforced concrete buildings based on statistics of structural lateral resistance. Structural Safety, 19(1), 141-151. http://dx.doi.org/10.1016/S0167-4730(96)00027-6

Sasani, M., Kiureghian, A. D., \& Bertero. V. V. (2002). Seismic fragility of short period reinforced concrete structural walls under near-source ground motions. Structural Safety, 24(2-4), 123-138. http://dx.doi.org/10.1016/S0167-4730(02)00021-8

Sheng, Z., Xie, S. Q., \& Pan, C. Y. (2008). Probability theory and mathematical statistics (4th ed., pp. 106-110). Beijing: Higher Education Press.

Wang, D. W. (2001). Analysis of Some Failure of Building Structures. World Information of Earthquake Engineering, 12(1), 112-114.

Wang, G. Y., \& Zhu, J. H. (1998). Approximate Method Dealing with Failure Dependence among Structures in Disaster-Resistant Engineering System. Earthquake Engineering and Engineering Vibration, 18(4), 1-7.

Wu, S. W. (1990). Structural reliability analysis (pp. 127-129). Beijing: China Communication Press. 